LXXXVII.-Experiments on the Synthesis of the Terpenes. Part VII. A Synthesis of Tertiary Menthol (p-Menthanol-4) and of Inactive Menthene ( $\Delta^{3}-$ $\mathrm{p}$-Menthene).

By William Henry Perkin, jun.

Menthene was discovered in the year 1839 by Walter (Annalen, 32, 289 ), who obtained it from menthol by heating with sulphuric acid or 
phosphorus pentoxide. It is readily prepared, in a yield of 80 per cent., by heating menthol with crystallised oxalic acid (Zelinsky and Zelikoff, Ber., 1901, 34, 3253), and is described as a colourless oil which distils at $167^{\circ}$ and has a faint odour of peppermint.

Menthene has been the subject of repeated investigation, but its constitution was first proved by Wagner, who showed that when oxidised by potassium permanganate it yields the following degradation products :

$$
\begin{aligned}
& \mathrm{Me} \cdot \mathrm{CH}<\underset{\mathrm{CH}_{2} \cdot \mathrm{CH}_{2}}{\mathrm{CH}_{2}-\mathrm{CH}}>\mathrm{CHMe} \\
& \Delta^{3}-p \text {-Menthene. } \\
& \mathrm{Me} \cdot \mathrm{CH}<\mathrm{CH}_{2}-\mathrm{CH}_{2} \cdot \mathrm{CH}(\mathrm{OH})>\mathrm{CH}(\mathrm{OH}) \cdot \mathrm{CHMe}_{2} \\
& \text { Menthandiol }(3: 4) \text {. }
\end{aligned}
$$

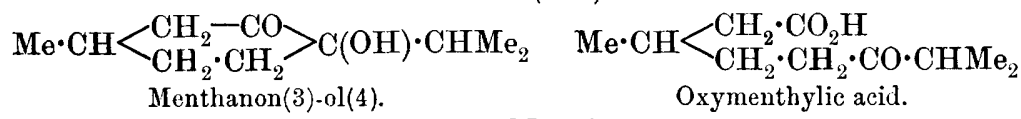

$$
\begin{aligned}
& \mathrm{Me} \cdot \mathrm{CH}<\frac{\mathrm{CH}_{2} \cdot \mathrm{CH}_{2} \cdot \mathrm{CO}_{2} \mathrm{H}}{\mathrm{CH}_{2}} \\
& \beta \text {-Methyladipic acid. }
\end{aligned}
$$

Tertiary menthol was first prepared by Baeyer (Ber., 1893, 26, 2270 and 2560) by an interesting series of reactions which will be readily understood with the aid of the following formulæ :

$$
\mathrm{Me} \cdot \mathrm{CH}\left\langle\mathrm{CH}_{2} \frac{\mathrm{CH}_{2}}{\mathrm{CH}_{\text {Menthol. }}} \stackrel{\mathrm{CH}(\mathrm{OH})}{\mathrm{CH}_{2}}>\mathrm{CH} \cdot \mathrm{CHMe}_{2}\right.
$$

$$
\begin{aligned}
& \mathrm{Me} \cdot \mathrm{CH}\left\langle\underset{\mathrm{CH}_{2}-\mathrm{CH}_{2}}{\mathrm{CH}_{2} \cdot \mathrm{CHI}}>\mathrm{CH} \cdot \mathrm{CHMe}\right. \\
& \text { Menthyliodide. } \\
& \begin{array}{c}
\mathrm{Me} \cdot \mathrm{CH} \\
\underset{\Delta^{3}-p-\text { Menthene. }}{\mathrm{CH}_{2} \cdot \mathrm{CH}_{2}}>\mathrm{C} \cdot \mathrm{CHMe}_{2} \\
\mathrm{CH}_{2}
\end{array}
\end{aligned}
$$

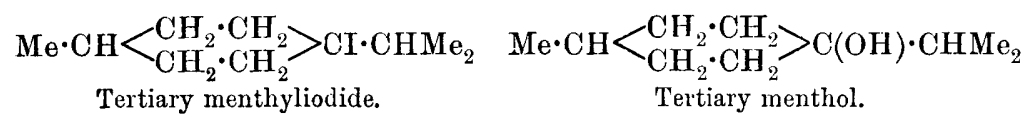

By acting on tertiary menthol with hydrobromic acid, Baeyer obtained tertiary menthyl bromide, and showed that when this bromide is digested with quinoline it yields menthene, and since tertiary menthol is necessarily inactive, it follows that the menthene obtained from it must also be the inactive modification.

Menthene has always taken a leading part in the historical development of the chemistry of the terpenes, and is undoubtedly the most important of the tetrahydro-derivatives of cymene; for this reason it was thought interesting to attempt its synthesis, and ultimately the problem was solved by means of the following series of reactions.

Hexahydro- $p$-toluic acid is converted into a-bromohexahydro $p$-toluic 
acid by the action of phosphorus pentachloride and bromine, and the bromo-acid is then treated, in the cold, with caustic potash, when it is readily converted into a mixture of a-hydroxyhexahydro-p-tıluic acid and $\Delta^{1}$-tetrahydro-p-toluic acid:<smiles>CC(C)CCC(CCCC(=O)O)CCC(CCCC(=O)O)C(=O)O</smiles>

The hydroxy-acid is readily attacked by cold sulphuric acid with evolution of carbonic oxide and formation of p-methylcyclohexanone,

$$
\mathrm{Me} \cdot \mathrm{CH}<\mathrm{CH}_{2} \cdot \mathrm{CH}_{2} \cdot \mathrm{CH}_{2}>\mathrm{CO},
$$

a colourless, pleasant-smelling oil which distils at $170^{\circ}$, and has already been described by Sabatier and Mailhe (p. 783).

When this ketone is added to an ethereal solution of magnesium isopropyl iodide, it is at once converted into tertiary menthol,

$$
\mathrm{Me} \cdot \mathrm{CH}\left\langle\mathrm{CH}_{2} \cdot \mathrm{CH}_{2} \cdot \mathrm{CH}_{2}>\mathrm{C}(\mathrm{OH}) \cdot \mathrm{CHMe}_{2}\right. \text {. }
$$

The alcohol obtained in this way had a pleasant odour of peppermint, distilled at $97^{\circ}(25 \mathrm{~mm}$.), and did not solidify in a freezing mixture, and further comparison showed that its properties agreed exactly with those of the tertiary menthol which Baeyer had obtained from menthol by the process mentioned above. Finally, a quantity of synthetical tertiary menthol was digested with potassium hydrogen sulphate, when it was converted, by elimination of water, into inactive menthene,

$$
\mathrm{Me} \cdot \mathrm{CH}<\mathrm{CH}_{2} \cdot \mathrm{CH}_{2}-\mathrm{CH}>\mathrm{C} \cdot \mathrm{CHMe}_{2} .
$$

The synthetical hydrocarbon distilled at $168^{\circ}$ and yielded the nitrosochloride of melting point $128^{\circ}$, which is so characteristic of inactive menthene.

\section{a-Bromohexahydro-p-toluic Acid.}

The method employed in the preparation of this acid is that described in detail in Part II of these researches (Perkin and Pickles, Trans., 1905, 87, 644), and consists in treating hexahydro-p-toluic acid first with phosphorus pentachloride and then with bromine at $100^{\circ}$. The crude bromo-acid is dissolved in boiling light petroleum (b. p. $\left.50-60^{\circ}\right)$, and the solution, after shaking with animal charcoal, filtered and cooled in ice-water, when, especially if the solution is vigorously stirred with a glass rod, the bromo-acid soon crystallises in groups of 
stars. After two further crystallisations from the same solvent, the acid was analysed with the following results :

$0 \cdot 1988$ gave $0 \cdot 1699 \mathrm{AgBr} . \quad \mathrm{Br}=36 \cdot 3$.

$\mathrm{C}_{8} \mathrm{H}_{13} \mathrm{O}_{2} \mathrm{Br}$ requires $\mathrm{Br}=36 \cdot 2$ per cent.

$\alpha$-Bromohexahydro-p-toluic acid melts at $109^{\circ}$ and is readily soluble in ether, benzene, alcohol, or chloroform, but rather sparingly so in light petroleum or formic acid in the cold. It crystallises from formic acid in striated leaflets which resemble crystals of benzoic acid.

The bromination of hexahydro- $p$-toluic acid was first investigated by Einhorn and Willstätter (Annalen, 1894, 280, 161), who obtained an $a$-bromohexahydro- $p$-toluic acid which, after three crystallisations from formic acid, melted at $71-72^{\circ}$. The considerable discrepancy in melting point may possibly be due to stereoisomerism, that is, the substance obtained by Einhorn and Willstätter may be the cis-, and that described in the present paper the trans-modification of $a$-bromohexahydro- $p$-toluic acid. In order to obtain evidence on this point, the mother liquors of the acid of melting point $109^{\circ}$ were very carefully examined. The light petroleum was allowed to evaporate at the ordinary temperature, and the solid residue, which contained only traces of oil, was fractionally crystallised from formic acid.

In this way considerable quantities of the acid of melting point $109^{\circ}$ were isolated, but, although there was evidence of the existence of a second acid, it was present in such small quantities that it was impossible to obtain it in a pure state.

\section{a-Hydroxyhexahydro-p-toluic Acid.}

When $\alpha$-bromohexahydro- $p$-toluic acid is ground to a paste with water and mixed with an excess of dilute caustic soda, it gradually dissolves, and after standing for three days at the ordinary temperature, and being subsequently heated for half an hour on the water-bath, it will have been completely decomposed with formation of a mixture of the sodium salts of $a$-hydroxyhexahydro- $p$-toluic acid and $\Delta^{1}$-tetrahydro- $p$-toluic acid. After cooling and acidifying, the solution deposits a precipitate which is sometimes so finely divided that it is difficult to collect, but if the whole is heated for half an hour on the water-bath and then allowed to remain for twenty-four hours this difficulty is overcome. The precipitate is washed with water and crystallised from light petroleum, when colourless prisms are obtained, which melt at $134^{\circ}$ and consist of $\Delta^{1}$-tetrahydro-p-toluic acid (compare Perkin and Pickles, Trans., 1905, $87,646)$.

0.1359 gave $0.3408 \mathrm{CO}_{2}$ and $0.1047 \mathrm{H}_{2} \mathrm{O} . \mathrm{C}=68.4 ; \mathrm{H}=8.5$. $\mathrm{C}_{3} \mathrm{H}_{12} \mathrm{O}_{2}$ requires $\mathrm{C}=68.6 ; \mathrm{H}=8.6$ per cent. 
The aqueous filtrate from this acid was extracted five times with ether, the ethereal solution evaporated, and the residual syrupy mass distilled in steam until the tetrahydro-p-toluic acid which it contained had been completely removed. The residue was again extracted with ether and the dried ethereal solution evaporated, when a thick syrup remained which soon solidified, and, after crystallising twice from a mixture of benzene and light petroleum and three times from water, the new hydroxy-acid was obtained pure in the form of pearly plates.

0.2078 gave $0.4632 \mathrm{CO}_{2}$ and $0.1668 \mathrm{H}_{2} \mathrm{O} . \mathrm{C}=60.8 ; \mathrm{H}=8.9$.

$0.1664 \Rightarrow 0.3703 \mathrm{CO}_{2}, 0.1336 \mathrm{H}_{2} \mathrm{O} . \quad \mathrm{C}=60.7 ; \mathrm{H}=8.9$. $\mathrm{C}_{8} \mathrm{H}_{14} \mathrm{O}_{3}$ requires $\mathrm{C}=60.8 ; \mathrm{H}=8.8$ per cent.

a-Hydroxyhexahydro-p-toluic acid melts at $130-132^{\circ}$ and is readily soluble in ether or alcohol, but sparingly so in cold water.

The silver salt, $\mathrm{C}_{8} \mathrm{H}_{13} \mathrm{O}_{3} \mathrm{Ag}$, is obtained, on the addition of silver nitrate to a warm slightly alkaline solution of the ammonium salt, as a curdy precipitate which soon breaks up into a satiny, crystalline mass. For analysis, the salt was dried at $100^{\circ}$.

$0 \cdot 4341$ gave $0 \cdot 1698 \mathrm{Ag} . \quad \mathrm{Ag}=40 \cdot 7$. $\mathrm{C}_{8} \mathrm{H}_{13} \mathrm{O}_{3} \mathrm{Ag}$ requires $\mathrm{Ag}=40 \cdot 7$ per cent.

The slightly alkaline solution of the ammonium salt shows the following behaviour. Barium chloride gives a white precipitate which dissolves in boiling water and separates, on slowly cooling, in beautiful colourless needles; calcium chloride also gives a similar precipitate which crystallises from water, but it is much more soluble than the barium salt. Copper sulphate yields a very pale blue precipitate which is almost insoluble in water, and lead acetate and zinc sulphate give white, curdy, insoluble precipitates.

\section{p-Methylcyclohexanone.}

In the introduction to this paper it is stated that $a$-hydroxyhexahydro- $p$-toluic acid is decomposed by concentrated sulphuric acid with formation of $p$-methylcyclohexanone. Unfortunately, considerable quantities of tetrahydro- $p$-toluic acid are always produced at the same time, and the yield of ketone is therefore unsatisfactory and rarely more than 30 per cent. of that theoretically possible.

The finely-powdered hydroxy-acid is added in small quantities at a time to about ten times its weight of sulphuric acid, which is kept at $-10^{\circ}$ by means of ice and salt. As soon as the whole has been added, the flask is taken from the freezing mixture and shaken until the acid has been completely decomposed, which is the case in about twenty to thirty minutes; the clear brown solution is then poured into ice and water and distilled in steam. 
At first the ketone passes over with the condensed water, afterwards the tetrahydro-p-toluic acid separates in the condenser and distillate in the form of crystals. The distillate is saturated with salt and extracted twice with ether; the ethereal solution is repeatedly washed with sodium carbonate, ${ }^{*}$ dried over calcium chloride and evaporated, and the ketone purified by repeated distillation, when, with the exception of a small amount of a condensation product of boiling point $243-245^{\circ}$, almost the whole quantity passes over at $170^{\circ}(773 \mathrm{~mm}$.).

0.1241 gave $0.3412 \mathrm{CO}_{2}$ and $0.1208 \mathrm{H}_{2} \mathrm{O} . \mathrm{C}=74.8 ; \mathrm{H}=10.8$. $\mathrm{C}_{7} \mathrm{H}_{12} \mathrm{O}$ requires $\mathrm{C}=74.9 ; \mathrm{H}=10.8$ per cent.

p-Methylcyclohexanone has a pleasant and characteristic odour which somewhat resembles that of peppermint; when it is mixed with a solution of semicarbazide hydrochloride and sodium acetate, combination takes place at once, and the very sparingly soluble semicarbazone separates as a crystalline powder. This was collected, crystallised from much alcohol, and the glistening, sandy powder analysed with the following result :

0.1114 gave 23.8 c.c. of nitrogen at $14^{\circ}$ and $750 \mathrm{~mm}$. $\mathrm{N}=\mathbf{2 5} \cdot 0$. $\mathrm{C}_{8} \mathrm{H}_{15} \mathrm{ON}_{3}$ requires $\mathrm{N}=24 \cdot 8$ per cent.

p-Methylcyclohexanone semicarbazone is very sparingly soluble in cold alcohol and melts at about $198^{\circ}$ with decomposition.

$p$-Methylcyclohexanone had been previously obtained by Sabatier and Mailhe (Compt. rend., 1905, 140, 350-352), who prepared it by reducing $p$-cresol with hydrogen in the presence of nickel and subsequent oxidation. They give the boiling point of the ketone as $169 \cdot 5^{\circ}$ and the melting point of the semicarbazone as $197^{\circ}$, and these properties agree almost exactly with those found in the case of the $p$-methylcyclohexanone produced by the method described above.

\section{Inactive Tertiary Menthol and Inactive Menthene.}

In carrying out the synthesis of tertiary menthol, pure $p$-methylcyclohexanone (17 grams) was gradually added to an ethereal solution of magnesium isopropyl iodide (containing 10 grams of magnesium), care being taken to avoid rise of temperature during the addition.

After remaining for three hours, the product was decomposed by water and dilute hydrochloric acid, the ethereal solution washed well with water, dried over calcium chloride, evaporated, and the residual oil twice fractionated under reduced pressure. In this way, about

* When the sodium carbonate extract is acidified, the tetrahydro-p-toluic acid separates at once and, after recrystallising from dilute acetic acid, is pure and melts at $134^{\circ}$. 
8 grams of a colourless oil were obtained which contained no unchanged $p$-methylcyclohexanone, distilled at $97^{\circ}(25 \mathrm{~mm}$.), and consisted of pure tertiary menthol.

$$
\begin{gathered}
0.1557 \text { gave } 0.4372 \mathrm{CO}_{2} \text { and } 0.1769 \mathrm{H}_{2} \mathrm{O} . \quad \mathrm{C}=76 \cdot 6 ; \mathrm{H}=12 \cdot 6 . \\
0.1714 \quad 0.4803 \mathrm{CO}_{2} \Rightarrow 0 \cdot 1958 \mathrm{H}_{2} \mathrm{O} . \quad \mathrm{C}=76.5 ; \mathrm{H}=12.7 . \\
\mathrm{C}_{10} \mathrm{H}_{20} \mathrm{O} \text { requires } \mathrm{C}=76.9 ; \mathrm{H}=12.8 \text { per cent. }
\end{gathered}
$$

Tertiary menthol is a syrup which possesses in a marked degree the pungent and pleasant odour of peppermint so characteristic of ordinary menthol. It decomposes on distillation under the ordinary pressure, but if the operation is very rapidly carried out a considerable quantity passes over at $207^{\circ}$, and yields on analysis numbers agreeing approximately with those given above. Several different specimens of tertiary menthol were prepared during this investigation, and many attempts were made to obtain it in a crystalline condition, but without success. Since, however, ordinary menthol solidifies so readily and is so closely related to tertiary menthol, it seems likely that the latter will ultimately also be found to crystallise.* Tertiary menthol was first prepared by Baeyer (Ber., 1893, 26, 2270), who obtained it from menthene by converting it first into menthyliodide, and then, by the action of silver acetate, into tertiary menthylacetate, which on hydrolysis yielded tertiary menthol (compare p. 779). Baeyer describes it as an oil, boiling at $97-101^{\circ}(20 \mathrm{~mm}$.), which did not crystallise even when cooled in solid carbonic anbydride.

The synthetical tertiary menthol, obtained as described above, was digested with twice its weight of powdered potassium hydrogen sulphate for one hour, the mass was then warmed with water until the salt had dissolved, and the whole distilled in steam. The distillate was extracted with ether, the ethereal solution dried over calcium chloride, evaporated, and the residue distilled, when almost the whole quantity passed over at $158-170^{\circ}$. This was distilled three times over sodium and the portion boiling at $167-168^{\circ}$ analysed.

$$
\begin{gathered}
0.1803 \text { gave } 0.5722 \mathrm{CO}_{2} \text { and } 0.2106 \mathrm{H}_{2} \mathrm{O} . \mathrm{C}=86.6 ; \mathrm{H}=12.9 . \\
0.1621 \Rightarrow \quad 0.5162 \mathrm{CO}_{2} \Rightarrow 0.1904 \mathrm{H}_{2} \mathrm{O} . \mathrm{C}=86.8 ; \mathrm{H}=13.1 . \\
\mathrm{C}_{10} \mathrm{H}_{18} \text { requires } \mathrm{C}=87.0 ; \mathrm{H}=13.0 \text { per cent. }
\end{gathered}
$$

In order to prove conclusively that this hydrocarbon was inactive menthene, it was converted into the characteristic nitrosochloride in the following way.

The hydrocarbon ( 2 c.c.) was dissolved in methyl alcohol (6 c.c.) and acetic acid (1 c.c.), mixed with freshly-distilled isoamyl nitrite (8 c.c.), and, after cooling to $-5^{\circ}$, concentrated hydrochloric acid (7 c.c.) was added drop by drop from a burette, the whole being well

* Compare Trans., 1905, 87, 1100, footnote. 
EXPERIMENTS ON THE SYNTHESIS OF THE TERPENES. 839

slaken during the addition. The product soon began to deposit crystals, and after one hour water was added, the semi-solid mass collected at the pump, and left in contact with porous porcelain until the oily impurity had been completely absorbed.

The colourless residue was then twice crystallised from boiling alcohol, in which this nitrosochloride is rather sparingly soluble.

$0 \cdot 2341$ gave $0 \cdot 1656 \mathrm{AgCl} . \quad \mathrm{Cl}=17 \cdot 5$.

$\mathrm{C}_{10} \mathrm{H}_{18} \mathrm{ONCl}$ requires $\mathrm{Cl}=17 \cdot 4$ per cent.

This nitrosochloride melted sharply at $128^{\circ}$, which is exactly the melting point of inactive menthene nitrosochloride (Urban and Kremers, Amer. Chem. J., 1894, 16, 395), so that there can be no doubt that the synthetical hydrocarbon is inactive menthene.

The Victoria University of Manchester. 